\title{
Abrupt luminance change pops out; abrupt color change does not
}

\author{
JAN THEEUWES \\ TNO Human Factors Research Institute, Soesterberg, The Netherlands
}

\begin{abstract}
The present studies investigated whether an isoluminant color change pops out, indicating that it can be detected preattentively in parallel. The results of Experiment 1 show that an abrupt color change presented on an equiluminant background does not pop out. However, when the color change is accompanied by a small luminance change, it does pop out. The results of Experiment 2 show that the pop-out is fully due to the luminance change and not to the color change. The results of Experiments 3 and 4 show that the failure to find a pop-out at equiluminance cannot be attributed to the limited temporal resolution for chromatic stimuli. The results of Experiment 5 show that particular search strategies cannot be responsible for the obtained results. The results are in agreement with physiological findings regarding the parvo and magno systems.
\end{abstract}

If a single red object is embedded in an array of green objects, it is seen immediately without effort; this phenomenon is known as visual pop-out (Treisman \& Gelade, 1980). One can speak of a pop-out when the time to detect the object is hardly affected by the number of elements in the display (less than 5 or $6 \mathrm{msec}$ per element; Treisman \& Souther, 1985). The object with a unique feature is detected through early, spatially parallel and automatic encoding, and its presence tends to call attention to itself (Treisman \& Gormican, 1988). This type of parallel preattentive processing is contrasted with attentive processing in which serial scanning through the display is necessary in order to detect the target. In the latter type of task, the time to find the object linearly increases with the number of elements in the display. The early perceptual preattentive encoding causing an object to pop out from its background is limited to a particular set of primitive features, such as orientation of edges, color, brightness, and shape.

Recent evidence shows that abrupt luminance onsets (e.g., Müller \& Rabbitt, 1989; Theeuwes, 1991b, 1994; Yantis \& Jonides, 1984), abrupt luminance offsets (Theeuwes, 199la), and abrupt luminance changes (Theeuwes, 1990) do pop out in an array of stationary elements that do not have a luminance change. It has been shown that abrupt onsets and offsets can capture attention in a stimulusdriven fashion, indicating that certain properties of the stimulus capture attention independently of the observer's intentions (e.g, Theeuwes, 1991b, 1994; Yantis \& Jonides, 1984, 1990; but see Folk, Remington, \& Johnston, 1992).

The author would like to thank Chip Folk, Nico A. Kaptein, Frank Kooi, Art Kramer, Marcel P. Lucassen, Roger Remington, Steven Yantis, and an anonymous reviewer for their comments and suggestions. Correspondence concerning this article should be addressed to Jan Theeuwes, TNO Human Factors Research Institute, P.O. Box 23, 3769 ZG Soesterberg, The Netherlands (e-mail: janthe@tm.tno.nl).
It has been suggested that an abrupt visual event captures attention by triggering the transient channels in the primate visual system (e.g., Breitmeyer \& Ganz, 1976; Todd \& Van Gelder, 1979; Yantis \& Jonides, 1984). Y cells or magno cells are at the basis of the transient channel, and these cells with their corresponding retinabrain pathways are particularly involved in luminance processing and respond selectively to abrupt changes in visual stimulation, such as onsets, offsets, and movement (e.g., Livingstone \& Hubel, 1988; Zeki \& Shipp, 1988). The magno system is basically color-blind and responds fast to temporal changes in luminance. X-cells or parvo-cells are at the basis of what is called the sustained channel. This channel is relatively slow and is particularly involved in processing detailed patterns and color information.

This physiological evidence is corroborated by psychophysical experiments on movement perception. For example, Cavanagh, Tyler, and Favreau (1984) showed that, relative to a nonequiluminant condition, the perceived velocity of moving red and green equiluminant sinewave bars was substantially slowed. The grating often appeared to be static. Subjects only appreciated some motion because they occasionally noticed that the bars had changed position. Recently, Lüschow and Nothdurft (1992) showed that subjects could not detect preattentively a single moving line in a stationary texture when present on an equiluminant background.

The present studies investigated the characteristics of the transient-sustained (magno-parvo) system in visual search. More specifically, it was tested whether abrupt color change at equiluminance can be detected when subjects are set to look for it. Subjects viewed a multielement display consisting of 4, 9, or 19 elements. After $50 \mathrm{msec}$ (Experiments 1 and 2) or $100 \mathrm{msec}$ (Experiments 3 and 4), an identical element was added to the display. The studies discussed above demonstrated that attention can be captured independently of the observer's intentions; however, in the present study, observers were 
set to detect this added element. All elements, including the added element, had either the same luminance as did the background (equiluminant) or either a higher or a lower luminance than the background.

If subjects are capable of responding to any abrupt temporal change occurring in the visual field, then one might expect that an abrupt color change does pop out and can attract attention. Alternatively, if a change in luminance is necessary to allow attention attraction, then it is expected that no pop-out occurs at equiluminance. Under the same conditions, a pop-out is expected when an abrupt luminance change is introduced.

The main interest of the present study was whether an abrupt change (luminance or color) does pop out and can be detected in parallel. In other words, when the target pops out, it must be ensured that the pop-out is due to the detection of the change and not to any other confounding factor. First, there might be confounding effects of memory. For example, it is possible that an object pops out because subjects notice that an element that previously was not present within the display has been added. In that case, subjects did not detect the actual change, but they inferred the change by comparing the two displays (as for example in Cavanagh et al., 1984). Second, it is possible that a colored element pops out because of local chromatic adaptation (Theeuwes \& Lucassen, 1993). For example, when subjects are looking at a display containing green elements against a gray background, subjects get adapted to the gray and green color. If one adds a new green-colored equiluminant element to such a display, the newly added green element will pop out not because subjects detected the change but because chromatic adaptation causes the newly added green element to have a color and luminance that are slightly different from those of the other green elements (i.e., a static odd-man-out). Theeuwes and Lucassen (1993) showed that chromatic adaptation to a display presented longer than $100 \mathrm{msec}$ can cause an element to pop out from an array of other identical elements.

In order to ensure that these confounding effects could not play a role, large irregular displays were used so that it was impossible to memorize and compare the sequentially presented pattern of elements. In addition, the target circle was added either $50 \mathrm{msec}$ (Experiments 1 and 2) or $100 \mathrm{msec}$ (Experiments 4 and 5) after display onsettimes too short for a chromatic adaptation to build up (e.g., Theeuwes \& Lucassen, 1993).

\section{METHOD}

\section{Experiment 1: Green Elements on a Gray Background}

Subjects. Two experienced observers (a graduate student, N.K., and the author, J.T.) and one naive subject (E.v.E.) participated in Experiments 1 and 3. In Experiment 2, only the two experienced observers participated. In Experiment 4, a naive and an experienced observer participated. In Experiment 5, two naive and one experienced observer participated. All had normal or corrected-tonormal visual acuity and reported having no color defects.

Apparatus and Stimuli. A NEC Multisync 3D VGA color CRT (resolution $640 \times 350$ ) controlled by an SX-386 Personal Com- puter (G2) was used for presenting the stimuli. The computer controlled the timing of the events, generated pictures, and recorded reaction times. The / key and the $z$ key of the computer keyboard were used as response buttons. Each subject was tested in a soundattenuated, dimly lit room. The subject's head rested on a chinrest. The CRT was located at eye level, $103 \mathrm{~cm}$ from the chinrest.

The display consisted of green outline circles (CIE $x, y$ chromaticity coordinates of $306 / .588$ ) presented on a gray background $(x, y=.259 / 277)$. The central fixation cross and line segments located within the outline circles of the search display were presented in red $(x, y=.548 / .407)$. The gray, red, and green colors were matched for luminance (approximately $17.0 \mathrm{~cd} / \mathrm{m}^{2}$ ) by means of a flicker fusion test (Ives, 1912). In this test, two color patches were presented at the same location in fast successive order $(60 \mathrm{~Hz})$. The subjects adjusted the brightness of one patch until the luminance flicker was at a minimum.

Procedure. The task was similar to that in Theeuwes (1991a, 1992; Theeuwes \& Lucassen, 1993), consisting of a visual search task in which there was a clear distinction between the defining and reported attribute of the target. The subjects responded to the orientation (horizontal or vertical) of the red line segment appearing in one of the circles of the search display. Because a horizontal or vertical target line segment does not pop out in a field of slightly tilted line segments, it was ensured that detecting the line segment required local focused attention (Theeuwes, $1991 \mathrm{a}$; Treisman \& Gormican, 1988). Throughout a trial, a fixation cross was presented at the center of the display. The search display consisted of 5,10 , or 20 green outline circles $\left(1.22^{\circ}\right.$ outside diameter and $1.10^{\circ}$ inside diameter), which were presented randomly at any of 30 locations in a $6 \times 5$ rectangular stimulus array $\left(10.1^{\circ} \times 7.0^{\circ}\right)$. Separation of nearest contours between the circles was $0.80^{\circ}$ in the $X$ direction, and $0.55^{\circ}$ in the $Y$ direction.

At the beginning of a trial, the fixation dot at the center of the screen was presented for $2,000 \mathrm{msec}$. Along with the fixation dot, a display was presented consisting of 4,9 , or 19 green outline circles, each containing a red line segment $\left(0.55^{\circ}\right)$ that was tilted $20^{\circ}$ to either side of the horizontal or vertical plane. The orientations were randomly distributed in a display. After $50 \mathrm{msec}$, an additional green outline target circle, containing either a horizontal or vertical line segment, was presented at one of the remaining empty locations of the $5 \times 6$ array. The line segment located in this added target circle determined the appropriate response key (the / key for vertical and the $z$ key for horizontal). The location of the added target circle containing the target line segment was randomized from trial to trial. Also, display size $(5,10,20)$ was randomized within blocks from trial to trial. The search display remained present until a response was emitted. If no response was made after $4 \mathrm{sec}$, the trial was counted as an error. Figure 1 provides an example of the trial events.

The luminance of both the added green outline circle and all other green circles was systematically varied between values above and below the luminance of the background. For each subject, the luminance value of green at equiluminance obtained by the flicker criterion was used as a starting point, and the smallest possible steps (given the equipment) in luminance change around the equiluminance criterion were determined. This resulted in four luminance steps below and four luminance steps above the background luminance. In addition, two baseline conditions were included: In one condition, the green-outline circle was presented at about half of the background luminance; in the other, the greenoutline circle was presented at about twice the background luminance. Subjects J.T. and N.K. performed all 11 luminance conditions. Subject E.v.E. performed 10 luminance conditions. Each luminance condition was run in a separate block of 90 trials, in which there were equal numbers of trials at each display size level $(5,10,20)$ and equal numbers of trials with a horizontal or vertical line segment. The order of presentation of the blocks was random. 


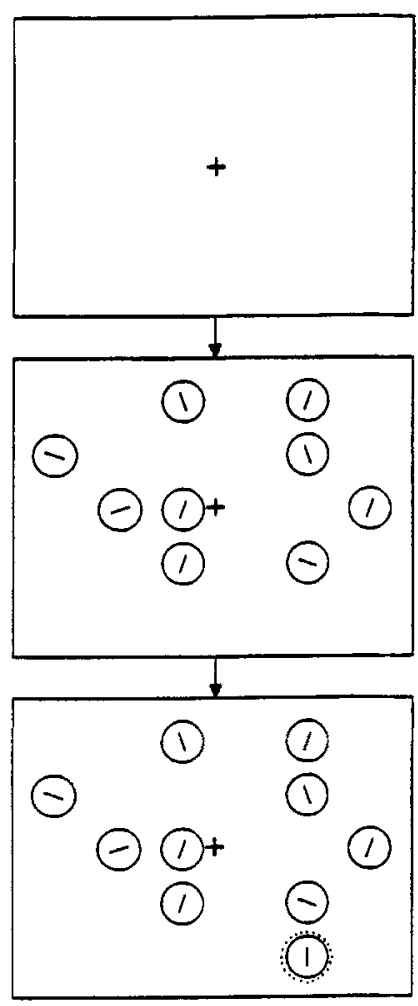

Figure 1. Example of trial events display size 10 . Initially, 9 circles are presented randomly at any of the 30 locations in a $6 \times 5$ rectangular stimulus array. After $\mathbf{5 0}$ msec, a circle with an identical color and luminance containing the response requiring line segment is presented at any of the remaining empty locations (in this particular example, at the bottom of the display).

It should be noted that in all conditions the added circle was equivalent both in color and in luminance to all other circles in the display. Thus, when the luminance of the added circle was decreased or increased, the luminance of the other circles was changed identically. Because the added circle was equivalent both in luminance and in color to the other circles, the added circle could only pop out when the subjects detected the abrupt change.

The outline circle to background luminance ratio $\left(L_{\text {circle }} / L_{\text {back- }}\right.$ ground ) was used as a contrast measure. Before each block of 90 trials, the luminance of the green circles was changed, and its colorimetric and photometric characteristics were measured by means of a spectro-radiometer (Photo Research, type: PR $703 \mathrm{~A} / \mathrm{M}$ ). Only the luminance of the green circle was changed but not its chromaticity coordinates. The luminance of the red line segments inside all green circles (including the added circle) was equiluminant with the background and remained constant during the whole experiment. Note that across luminance conditions, the luminance of the response requiring line segment remained constant and was equiluminant with the background.

Within each block of trials, there were short breaks after 45 trials in which the subjects received feedback about their performance (percentage errors and mean reaction time) on the preceding block of trials. The subjects were aware that the outline circle that was added $50 \mathrm{msec}$ later contained the response-requiring line segment. They were instructed to look for the added circle. Both speed and accuracy were emphasized. A warning beep informed the subject that an error had been committed.

\section{Experiment 2: Gray Elements on a Gray Background}

Experiment 2 was identical to Experiment 1, except that the outline circles were now gray. The line segments in the outline circles were red equiluminant with the background (all colors had the same CIE values as in Experiment 1). Note that at equiluminance, the outline circles were identical to the background, so that the stimulus field only consisted of equiluminant red line segments. Subject J.T. performed 9 luminance conditions, Subject N.K. performed 10 luminance conditions.

\section{Experiment 3: Green Elements on a Gray Background With a 100-msec Interstimulus Interval}

Experiment 3 was identical to Experiment 1, except that the interstimulus interval (ISI) between the stimulus field and the target circle was $100 \mathrm{msec}$ instead of $50 \mathrm{msec}$. Both subjects performed 10 luminance conditions in a random order.

\section{Experiment 4: Detecting a Color Change of a Single Element}

Experiment 4 served as a control experiment in which the subjects had to detect an equiluminant color change of a single circle that was presented randomly at any of the 30 locations in the $6 \times 5$ rectangular stimulus array. At the beginning of a trial, a fixation dot was presented at the center of the screen for $2,000 \mathrm{msec}$. One hundred fifty milliseconds before display onset a black dot indicated the location where the circle would be presented. The black dot $\left(0.12^{\circ}\right)$ presented at the center of the impending circle served as an exogenous location cue to ensure that there was no spatial uncertainty regarding the location of the impending circle. Upon display onset, the black dot was extinguished and an equiluminant red or green circle was presented for either $0,17,33,50,67,83$, or $100 \mathrm{msec}$ immediately followed by an equiluminant green circle presented for $4 \mathrm{sec}$. The subjects indicated whether or not they saw a red circle preceding the green circle. The subjects performed 20 trials in each condition. The red- and green-outline circles and gray background were matched for luminance.

\section{Experiment 5: Green Elements on a Gray Background With a 100-msec Interstimulus Interval}

Experiment 5 was identical to Experiment 3, except that the subjects performed a fixed number of luminance conditions (Subject K.H. performed 7 conditions, and Subjects F.K. and N.K. performed 6 conditions), which were varied within one single block of trials. The luminances of the outline circles used in this experiment were close to the background luminance giving luminance contrast ratios ( $L_{\text {circle }} / L_{\text {background }}$ ), which were close to 1 . Each luminance condition consisted of 48 trials, with 16 trials in each display size condition.

\section{RESULTS AND DISCUSSION}

\section{Experiment 1}

The best-fitting linear search functions (reaction time as a function of number of elements in the display) were calculated for each subject, at each luminance contrast ratio. Table 1 gives the search slopes, intercepts, and error rates.

Figure 2 presents these slopes as a function of luminance contrast ratio $\left(L_{\text {circle }} / L_{\text {background }}\right)$. The dotted lines in Figure 2 indicate the 6 -msec/element slope. Search functions with slopes less than $6 \mathrm{msec} / \mathrm{element}$ are considered to be characteristic of search processes for elements that pop out. As is clear from Figure 2, at near equiluminance, the target element does not pop out and serial search is required to detect the target. 
Table 1

Slopes, Intercepts, and Error Scores for the Various Contrast Ratios $\left(\boldsymbol{L}_{\text {cincle }} / \boldsymbol{L}_{\text {background }}\right)$ in Experiment 1

\begin{tabular}{|c|c|c|c|}
\hline Luminance Contrast & Intercept* & Slopet & Error Score \\
\hline \multicolumn{4}{|c|}{ Subject J.T. } \\
\hline 0.46 & 465 & -0.11 & 9.0 \\
\hline 0.81 & 529 & -0.57 & 7.7 \\
\hline 0.86 & 576 & 1.21 & 6.4 \\
\hline 0.92 & 656 & 11.37 & 7.7 \\
\hline 0.99 & 564 & 51.74 & 5.1 \\
\hline 1.06 & 471 & 72.86 & 15.4 \\
\hline 1.13 & 804 & 30.90 & 2.6 \\
\hline 1.20 & 526 & 28.77 & 5.1 \\
\hline 1.27 & 575 & 3.68 & 7.7 \\
\hline 1.38 & 518 & -0.56 & 10.2 \\
\hline 1.98 & 448 & -0.26 & 7.7 \\
\hline \multicolumn{4}{|c|}{ Subject N.K. } \\
\hline 0.45 & 583 & -1.46 & 6.4 \\
\hline 0.68 & 709 & -0.22 & 6.4 \\
\hline 0.81 & 597 & 7.39 & 6.4 \\
\hline 0.87 & 576 & 18.29 & 7.7 \\
\hline 0.92 & 528 & 41.69 & 7.7 \\
\hline 1 & 529 & 49.00 & 7.7 \\
\hline 1.07 & 586 & 64.72 & 9.0 \\
\hline 1.13 & 631 & 29.08 & 9.0 \\
\hline 1.18 & 625 & 31.06 & 6.4 \\
\hline 1.37 & 683 & 8.51 & 9.0 \\
\hline 1.83 & 621 & 0.47 & 7.7 \\
\hline \multicolumn{4}{|c|}{ Subject E.v.E. } \\
\hline 0.49 & 570 & -1.65 & 0.0 \\
\hline 0.84 & 589 & -4.45 & 2.5 \\
\hline 0.93 & 569 & -0.67 & 3.8 \\
\hline 1.00 & 610 & 1.40 & 1.3 \\
\hline 1.08 & 590 & 9.17 & 3.8 \\
\hline 1.16 & 656 & 24.80 & 6.4 \\
\hline 1.21 & 562 & 14.76 & 3.8 \\
\hline 1.34 & 504 & 6.52 & 2.6 \\
\hline 1.43 & 574 & 0.45 & 1.3 \\
\hline 2.04 & 602 & -0.70 & 1.3 \\
\hline
\end{tabular}

"Intercept values are given in milliseconds. †Slope values are given in milliseconds/element. ‡Error scores are precentages.

When a difference in luminance contrast is introduced, the search functions become flat, indicating that the target element starts to pop out. With small contrast ratios (between 0.8 and 1.2), search functions that can be thought of as mixtures of complete serial search, as found for the equiluminant condition (slopes of $20-80 \mathrm{msec} /$ element), and complete parallel search (less than $6 \mathrm{msec} /$ element), as found for the larger contrast ratios (less then 0.8 and more than 1.2). Such a mixture might possibly occur because, only on some trials, attention is attracted to the target element. Alternatively, because the pop-out is relatively weak, attention might be attracted to an approximate area where the added element is located, requiring still some serial search to exactly locate the target.

\section{Experiment 2}

Table 2 gives the search slopes, intercepts, and error scores for Experiment 2. Figure 3 presents the slopes as a function of contrast ratio $\left(L_{\text {circle }} / L_{\text {background }}\right)$. The longest search time is to be found at a luminance ratio of 1 , because then the gray circles are identical to the background. In this condition, the stimulus field consists of equiluminant red line segments. The line segment that is added later obviously does not pop out on an equiluminant background, a result that confirms the findings of Experiment 1. Figure 3 is comparable to Figure 2, suggesting that the pop-out observed in Experiment 1 was completely due to the difference in luminance and not to the difference in color. An equiluminant color change has obviously no access to the preattentive system that can signal the presence of the added element.

\section{Experiment 3}

The 100-msec display-to-target circle interval was included because it is possible that in Experiments 1 and 2 the target circle at equiluminance did not pop out because it was presented with such a short interval. In order to ensure that the absence of a pop-out at equiluminance is not due to limitations in the time domain (e.g., at 50msec ISI, the target circle does not pop out because it $a p$ pears to be presented at the same time as the stimulus display), Experiment 3 with an ISI of $100 \mathrm{msec}$ was included. Note that increasing the interval beyond $100 \mathrm{msec}$ might result in chromatic adaptation, which by itself will result in a pop-out of the target circle (Theeuwes \& Lucassen, 1993).

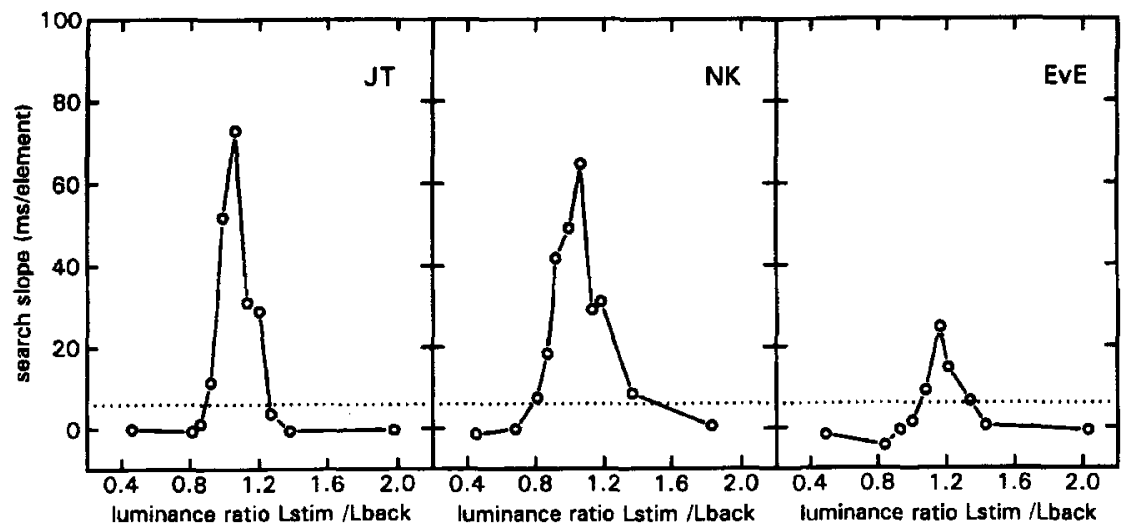

Figure 2. Experiment 1: Search slopes as a function of the contrast ratio for Observers J.T., N.K., and E.v.E. 
Table 2

Slopes, Intercepts, and Error Scores for the Various Contrast Ratios $\left(L_{\text {circle }} / L_{\text {backgound }}\right)$ in Experiment 2

\begin{tabular}{ccrr}
\hline Luminance Contrast & Intercept $^{*}$ & Slopet & Error Score \\
\hline & Subject J.T. & & \\
0.51 & 446 & -0.41 & 8.9 \\
0.75 & 481 & 2.85 & 7.7 \\
0.85 & 587 & 5.01 & 6.4 \\
0.89 & 441 & 57.22 & 1.2 \\
1.00 & 543 & 67.77 & 12.8 \\
1.07 & 749 & 43.62 & 3.8 \\
1.15 & 511 & 14.19 & 9.0 \\
1.21 & 531 & 3.21 & 7.7 \\
2.01 & 481 & 2.22 & 10.2 \\
& Subject N.K. & & \\
0.51 & 540 & -2.22 & 11.5 \\
0.77 & 587 & -0.72 & 7.7 \\
0.83 & 592 & 7.17 & 9.0 \\
0.90 & 657 & 21.06 & 6.4 \\
1.00 & 568 & 36.89 & 5.1 \\
1.07 & 469 & 26.84 & 10.2 \\
1.14 & 623 & 15.2 & 9.0 \\
1.23 & 566 & 7.5 & 9.0 \\
1.36 & 508 & 1.86 & 15.4 \\
2.01 & 502 & -1.28 & 10.2 \\
\hline
\end{tabular}

${ }^{*}$ Intercept values are given in milliseconds. ${ }^{+}$Slope values are given in milliseconds/element. \#Error scores are precentages.

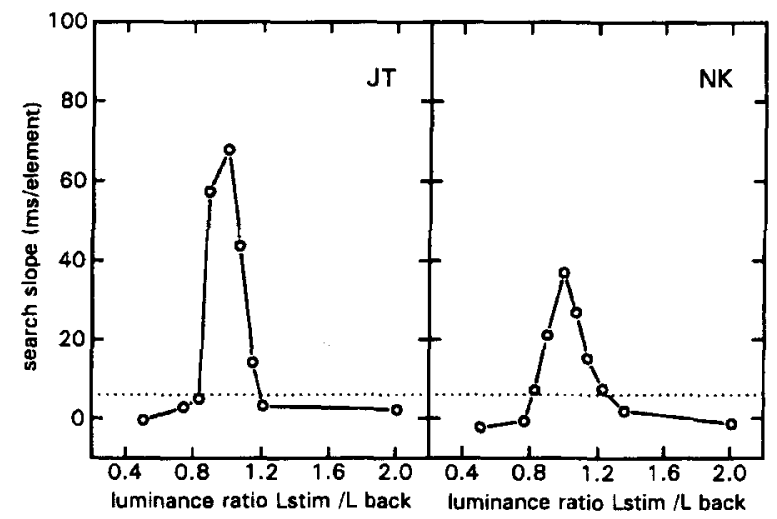

Figure 3. Experiment 2: Search slopes as a function of the contrast ratio for Observers J.T. and N.K.

The results of this experiment are presented in Table 3 and Figure 4 . The longest search time is to be found at near equiluminance. The results are comparable to those obtained in Experiments 1 and 2, suggesting that a longer ISI does not change the overall pattern of results.

\section{Experiment 4}

Experiment 4 served as a control experiment to ensure that the limited temporal resolution of the color system cannot account for the absence of the color pop-out. Kelly (1983) showed that there is little or no response for detecting red/green chromatic flicker beyond $15 \mathrm{~Hz}$ (a temporal cycle of $66 \mathrm{msec}$ ). This implies that the color system cannot detect color changes that are smaller than $33 \mathrm{msec}$ (half a temporal cycle). Although the 50- and 100 -msec ISIs applied in Experiments 1 and 3 are clearly beyond the critical interval of $33 \mathrm{msec}$, it is not quite clear to what extent the findings of Kelly (1983) on detecting red/green chromatic flicker generalize to the present conditions.

Figure 5 gives the results of Experiment 4 in which the subjects had to detect a red-to-green equiluminant color change of a single circle. As is clear from Figure 5, when the red circle was presented for $50 \mathrm{msec}$, the subjects could detect it at all trials. When the circle is presented around the critical (red/green chromatic flicker) interval of $33 \mathrm{msec}$ (Kelly, 1983) performance drops to about $80 \%$, suggesting that the present results are similar to those reported by Kelly. The results clearly indicate that the absence of a pop-out at equiluminance, as found in Experiments $1-3$, is not due to the limited temporal resolution for detecting chromatic stimuli.

\section{Experiment 5}

In Experiments 1-3, the subjects knew before each block of trials which luminance condition they would receive on a next block of trials. Although the subjects had the explicit instruction to look for the new element, knowing what luminance condition they would receive

Table 3

Slopes, Intercepts, and Error Scores for the Various Contrast Ratios ( $\left.L_{\text {circk }} / L_{\text {background }}\right)$ in Experiment 3

\begin{tabular}{|c|c|c|c|}
\hline Luminance Contrast & Intercept* & Slope $†$ & Error Score \\
\hline \multicolumn{4}{|c|}{ Subject J.T. } \\
\hline 0.48 & 392 & 2.50 & 11.5 \\
\hline 0.81 & 479 & -1.26 & 6.4 \\
\hline 0.89 & 480 & -0.60 & 7.7 \\
\hline 0.95 & 464 & 13.02 & 5.1 \\
\hline 1.01 & 485 & 54.27 & 6.4 \\
\hline 1.09 & 671 & 15.78 & 7.7 \\
\hline 1.16 & 523 & 11.63 & 11.5 \\
\hline 1.23 & 502 & 6.29 & 6.4 \\
\hline 1.25 & 455 & 1.19 & 10.2 \\
\hline 2.00 & 444 & 0.36 & 10.2 \\
\hline \multicolumn{4}{|c|}{ Subject N.K. } \\
\hline 0.50 & 477 & 0.41 & 9.0 \\
\hline 0.82 & 499 & 2.50 & 7.7 \\
\hline 0.90 & 508 & -1.25 & 7.7 \\
\hline 0.96 & 544 & 2.10 & 5.1 \\
\hline 1.02 & 520 & 26.22 & 7.7 \\
\hline 1.09 & 611 & 23.19 & 11.5 \\
\hline 1.16 & 437 & 27.27 & 10.2 \\
\hline 1.23 & 620 & -1.64 & 14.1 \\
\hline 1.32 & 531 & 1.38 & 7.7 \\
\hline 2.04 & 491 & 1.20 & 9.0 \\
\hline \multicolumn{4}{|c|}{ Subject E.v.E. } \\
\hline 0.49 & 539 & -2.05 & 2.5 \\
\hline 0.84 & 537 & 1.22 & 0.0 \\
\hline 0.93 & 603 & -0.26 & 0.0 \\
\hline 1.00 & 587 & -1.69 & 3.8 \\
\hline 1.08 & 442 & 31.92 & 1.3 \\
\hline 1.16 & 636 & 10.90 & 2.6 \\
\hline 1.21 & 654 & -0.62 & 1.3 \\
\hline 1.34 & 566 & -0.91 & 5.1 \\
\hline 1.43 & 576 & -4.69 & 0.0 \\
\hline 2.04 & 526 & -1.83 & 5.1 \\
\hline
\end{tabular}

"Intercept values are given in milliseconds. ${ }^{+}$Slope values are given in milliseconds/element. †Error scores are precentages. 


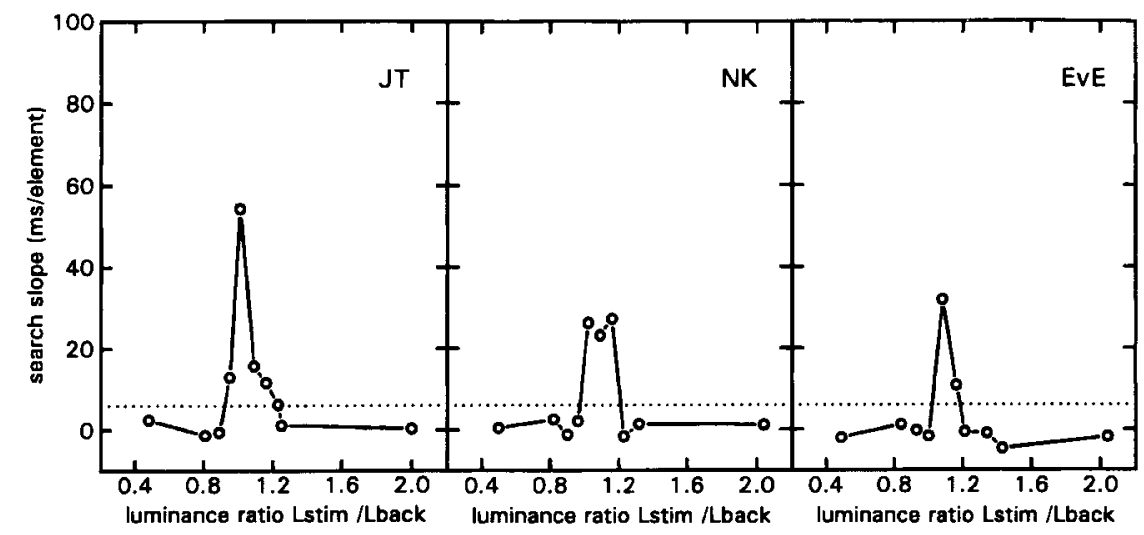

Figure 4. Experiment 3: Search slopes as a function of the contrast ratio for Observers J.T., N.K., and E.v.E.

might have induced a particular search strategy (e.g., knowing that search is difficult might have induced a serial search strategy). Experiment 5, in which luminance conditions were varied within one block of trials, was included to make sure that these strategies could not play a role.

Table 4 and Figure 6 give the results. As is clear from Figure 6, the results are comparable to those obtained in Experiment 3, suggesting that the above-mentioned search strategies do not play a significant role. Table 4 also gives the number of errors as a function of display size (the error search slopes). As evident from Table 4, in the high- and low-contrast conditions, the error search slopes were small (all except one were negative or zero), suggesting that the fast RTs in the large display size conditions were not due to trading speed for accuracy.

\section{GENERAL DISCUSSION}

The present study was designed to examine whether equiluminant color changes can be detected in parallel. The results clearly indicate that this is not possible: even when observers are set to detect the color change, they are unable to do so. Equiluminant color change obviously has no access to the preattentive system that can signal the presence of the added element. Experiments 3 and 4 show that the failure to find a pop-out at equiluminance cannot be attributed to the limited temporal resolution for chromatic stimuli. The results indicate that the color change did not pop out because it was presented at equiluminance with its background.

It should be noted that in all conditions the color and the luminance of the added circle were identical to the color and the luminance of all other circles. This guarantees that if the added circle pops out, it can only have been based on the detection of the abrupt color or abrupt luminance change. If subjects fail to see the change, then there is nothing in the display that makes the added circle different from the other circles. Failure to see the change necessarily results in serial search as demonstrated in conditions at near equiluminance. This is also the reason that it is impossible to increase the display-totarget circle interval beyond $100 \mathrm{msec}$. If target circle is added to the display at an interval larger than $100 \mathrm{msec}$, the color and the luminance of the added circle will look different from the color and the luminance of the circles that are already present on the display. Because the receptors locally adapt to the green circles that are already on the display, the newly added circle will look greener and brighter than the other circles. Theeuwes and Lucassen (1993) showed that when the adaptation time is longer than $100 \mathrm{msec}$, this local chromatic adaptation is strong enough to let an element presented at this locally adapted location pop out from a field of identical other elements. If, in the present experiments, an interval longer than $100 \mathrm{msec}$ would have been used, then the newly added circle would have popped out not because subjects would have detected the change but because the circle would have looked different from the other circles (i.e., a static odd-man-out).

Previous studies have focused on whether abrupt onsets capture attention independently of the observer's intentions. Thus, when the observer's task does not require a deliberate attentional set, abrupt onset singletons cap-

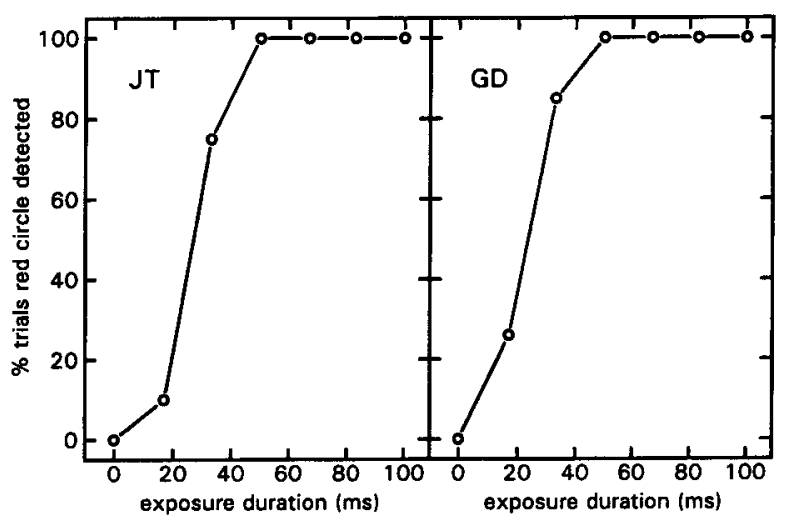

Figure 5. Experiment 4: Percentage of trials in which the red circle was detected as a function of its exposure duration for Observers J.T. and G.D. 
Table 4

Slopes, Intercepts, Error Scores, and Error Slopes for the Various Contrast

\begin{tabular}{|c|c|c|c|c|}
\hline Luminance Contrast & Intercept* & Slope $†$ & Error Score & Error Slopes $\S$ \\
\hline \multicolumn{5}{|c|}{ Subject K.H. } \\
\hline 0.94 & 601 & -1.87 & 8.4 & -0.62 \\
\hline 1.01 & 494 & 9.55 & 6.3 & 0.80 \\
\hline 1.07 & 496 & 37.70 & 4.2 & 0.36 \\
\hline 1.16 & 420 & 41.85 & 10.4 & -0.98 \\
\hline 1.20 & 471 & 19.17 & 2.1 & -0.01 \\
\hline 1.34 & 566 & 11.72 & 2.1 & 0.44 \\
\hline 1.41 & 586 & -1.59 & 2.1 & 0.44 \\
\hline \multicolumn{5}{|c|}{ Subject F.K. } \\
\hline 0.94 & 687 & -9.50 & 6.3 & -0.26 \\
\hline 1.01 & 540 & 10.77 & 8.3 & 0.71 \\
\hline 1.07 & 570 & 6.33 & 4.2 & -0.44 \\
\hline 1.16 & 575 & 23.43 & 4.2 & 0.08 \\
\hline 1.20 & 515 & 35.20 & 4.2 & 0.35 \\
\hline 1.34 & 646 & -3.18 & 0.0 & 0.00 \\
\hline \multicolumn{5}{|c|}{ Subject N.K. } \\
\hline 0.94 & 582 & -1.28 & 0.0 & 0.00 \\
\hline 1.01 & 464 & 13.63 & 8.3 & 0.17 \\
\hline 1.07 & 478 & 17.30 & 4.2 & 0.08 \\
\hline 1.16 & 488 & 25.00 & 2.1 & -0.35 \\
\hline 1.20 & 557 & 10.55 & 4.2 & -0.17 \\
\hline 1.34 & 544 & 8.23 & 0.0 & 0.00 \\
\hline
\end{tabular}

"Intercept values are given in milliseconds. †'Slope values are given in milliseconds/element. ‡Error scores are percentages. §Error slopes are given in percentages/element.

ture attention (e.g., Theeuwes, 1991b; Yantis \& Jonides, 1984). As expected, the present study shows that abrupt onsets also capture attention when subjects are set to look for them. The present study indicates, however, that abrupt color changes do not attract attention even when subjects are set to look for them, a result which seems to be at odds with recent findings suggesting that the appearance of new objects rather than luminance increments is necessary to produce attentional capture (Yantis \& Hillstrom, 1994). For example, Yantis and Hillstrom (1994, Experiment 1, "texture condition") showed that a new element presented abruptly without any overall luminance increment captured attention independent of the observer's intentions. There was no luminance increment when the new element was presented because the new element was revealed by rearranging the distribution of pixels with that region. Therefore, at the level of the letter, there was no overall increment or decrement in luminance. Even though there was no luminance increment, the new element captured attention, a finding that suggests that attention is captured by "newness" and not by luminance increments.

It is not immediately clear why the present results do not show any capture of attention of the newly added element even when observers are set to look for them, a finding that does not corroborate Yantis and Hillstrom's

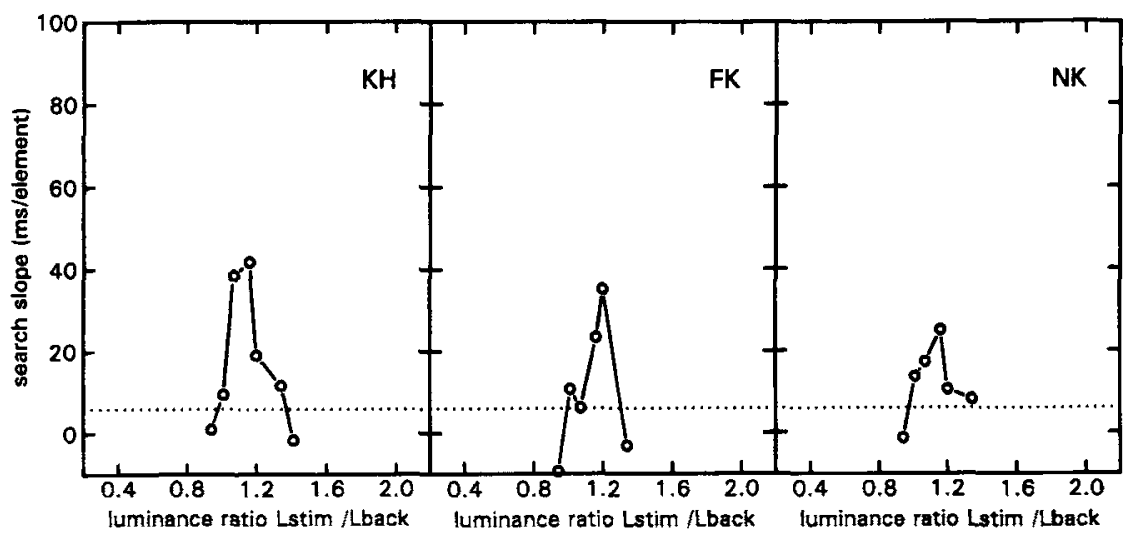

Figure 6. Experiment 5: Search slopes as a function of the contrast ratio for Observers K.H., F.K., and N.K. 
(1994) conclusions. There are, however, various differences between the present procedure and the one used by Yantis and Hillstrom (1994). First, it is possible that the Yantis and Hillstrom's "texture condition" of their Experiment 1 (a condition most comparable to the conditions used in the present study) did not render real equiluminance because pixels were locally redistributed. This procedure implies that at the location of the newly added letter, at pixel level, there were both abrupt onset and offset transients. Note that these local luminance changes did not occur at the locations of the old letters, indicating that there were local luminance changes specific to the newly added letter. Second, in all conditions of Yantis and Hillstrom's (1994) study, it is possible that the new element captured attention because observers noticed that an element that previously was not present in the display was added. In Yantis and Hillstrom's displays, this is likely because there were only a few elements present in the display (a maximum of 6) and the elements were presented in highly structured arrangement on an imaginary circle around the fixation dot. In this case, subjects might not have detected the appearance of a new element but inferred that an element was added by comparing the two displays. This strategy should break down when larger numbers of elements are present in the display and when the new element appears at a random location within the display, conditions employed in the present experiments.

The present findings indicating the absence of a popout at equiluminance are in agreement with physiological findings. The relatively slow parvo system, which is concerned with processing of color information, is not capable of preattentively triggering higher centers that something has changed. The data indicate, however, that a small luminance change is enough to trigger the luminancesensitive magno system, which immediately transmits signals to the brain, allowing the organism to orient and direct its attention to locations in visual space that potentially contain important information.

\section{REFERENCES}

BreITMEyer, B. C., \& GANZ, L. (1976). Implications of sustained and transient channels for theories of visual pattern masking, saccadic suppression, and information processing. Psychological Review, 83, $1-36$.

Cavanagh, P., Tyler, C. W., \& Favreau, O. E. (1984). Perceived velocity of moving chromatic gratings. Journal of the Optical Society of America, 8, 893-899.

Folk, C. L., Remington, R., \& Johnston, J. C. (1992). Involuntary covert orienting is contingent on attentional control settings. Journal of Experimental Psychology: Human Perception \& Performance, 18, 1030-1044.
IVES, H. E. (1912). Studies of the photometry of different colours: I. Spectral luminosity curves obtained by equality of brightness photometer and the flicker photometer under similar conditions. Philosophical Magazine, 24, 149-188.

KELLY, D. H. (1983). Spatiotemporal variation of chromatic and achromatic contrast thresholds. Journal of the Optical Society of America, 73, 742-750

Livingstone, M., \& Hubel, D. (1988). Segregation of form, color, movement, and depth: Anatomy, physiology, and perception. Science, 240, 740-749.

Lüschow, A., \& Nothdurf, H. C. (1992). Pop-out of orientation but no pop-out of motion at isoluminance. Vision Research, 33, 91-104.

MülleR, H. J., \& RABBiTT, P. M. A. (1989). Reflexive and voluntary orienting of attention: Time course of activation and resistance to interruption. Journal of Experimental Psychology: Human Perception \& Performance, 15, 315-330.

Theeuwes, J. (1990). Perceptual selectivity is task-dependent: Evidence from selective search. Acta Psychologica, 74, 81-99.

Theeuwes, J. (1991a). Cross-dimensional perceptual selectivity. Perception \& Psychophysics, 50, 184-193.

THEEUWES, J. (1991b). Exogenous and endogenous control of attention: The effect of visual onsets and offsets. Perception \& Psychophysics, 49, 83-90.

Theeuwes, J. (1992). Perceptual selectivity for color and form. Perception \& Psychophysics, 51, 599-606.

Theeuwes, J. (1994). Stimulus-driven capture and attentional set: Selective search for color and visual abrupt onset. Journal of Experimental Psychology: Human Perception \& Performance, 20, 799. 806.

Theeuwes, J., \& Lucassen, M. P. (1993). An adaptation-induced popout in visual search. Vision Research, 16, 2353-2357.

TodD, J. T., \& VAN Gelder, P. (1979). Implications of a sustainedtransient dichotomy for the measurement of human performance. Journal of Experimental Psychology: Human Perception \& Performance, 5, 625-638.

Treisman, A. M., \& Gelade, G. (1980). A feature integration theory of attention. Cognitive Psychology, 12, 97-136.

Treisman, A. M., \& Gormican, S. (1988). Feature search in early vision: Evidence from search asymmetries. Psychological Review, 95, $15-48$.

Treisman, A. M., \& Souther, J. (1985). Search asymmetry: A diagnostic for preattentive processing of separable features. Journal of Experimental Psychology: General, 114, 285-310.

Yantis, S., \& Hillstrom, A. P. (1994). Stimulus-driven attentional capture: Evidence from equiluminant visual objects. Journal of Experimental Psychology: Human Perception \& Performance, 20, $95-$ 108.

YANTIS, S., \& JONIDES, J. (1984). Abrupt visual onsets and selective attention: Evidence from selective search. Journal of Experimental Psychology: Human Perception \& Performance, 10, 601-621.

YANTIS, S., \& JoNIDES, J. (1990). Abrupt visual onsets and selective attention: Voluntary versus automatic allocation. Journal of Experimental Psychology: Human Perception \& Performance, 16, 121. 134.

ZeKI, S., \& SHIPP, S. (1988). The functional logic of cortical connections. Nature, 355, 311-317.

(Manuscript received November 1, 1993; revision accepted for publication December 24, 1994.) 